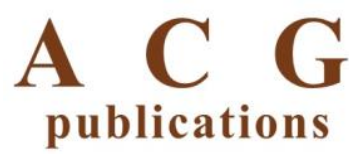

Rec. Nat. Prod. 13:6 (2019) 483-490

records of natural

products

\title{
A New Dimeric Sesquiterpenoid from Chloranthus japonicus Sieb.
}

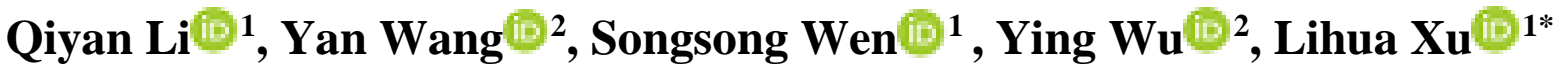 \\ and Zhenliang Sun ${ }^{3 *}$
}

${ }^{1}$ Health Food and Cosmetics Laboratory at Shandong Institute for Food and Drug Control, Jinan Shandong 250101, China

${ }^{2}$ Shanghai Putuo District Liqun Hospital, No.910, Tao-pu Road, Shanghai 200333, China

${ }^{3}$ Shanghai University of Medicine \& Health Science Affiliated sixth People's Hospital South Campus,

Shanghai 201499, China

(Received February 22, 2019; Revised April 13, 2019; Accepted April 13, 2019)

\begin{abstract}
Phytochemical investigation into the whole plants of Chloranthus japonicus Sieb. led to isolation and identification of a new dimeric lindenane sesquiterpenoid, named chlojapolactone B (1), and two new phenolic derivatives (2 and 3). Their chemical structures were elucidated on the basis of HRESIMS and NMR spectroscopic data, and the absolute configuration of $\mathbf{1}$ was determined using the electronic circular dichroism (ECD) analysis.
\end{abstract}

Keywords: Chloranthus japonicas; dimeric sesquiterpenoid; phenolic derivative. (C) 2019 ACG Publications. All rights reserved.

\section{Introduction}

Chloranthus japonicus Sieb., (Family: Chloranthaceae), is a perennial herb widely distributed in East Asia, including China, Japan, and Korea. In Chinese folklore medicines, this plant is commonly used for the treatment of traumatic injury, rheumatic arthralgia, fracture, pulmonary tuberculosis, and neurasthenia [1]. Previous phytochemical investigations have demonstrated that $C$. japonicus is enriched with sesquiterpenoids and sesquiterpenoid dimers [2-10]. A variety of sesquiterpenoids including eudesmane-, lindenane-, germacrane-, and acorane-, as well as lindenane-type sesquiterpenoid dimers and trimers with various bioactivities have been reported from this plant [1116]. Among them, dimers of lindenane-type sesquiterpenoid showed more significant bioactivities such as anti-HIV-1, anti-HCV, activated AMPK effects, anti-inflammatory, anti-tumor and DNA Topoisomerase I inhibitory activities $[3,9,15-18]$. In our phytochemical investigation on this plant for structurally intriguing and biologically important compounds, a new dimeric sesquiterpenoid (1) and two new phenolic derivatives ( $\mathbf{2}$ and $\mathbf{3}$ ) were obtained and characterized from the whole plants of C. japonicus. Herein, the isolation and structural elucidation of these compounds, together with their bioactivity evaluation, are described (Figure 1).

\footnotetext{
*Corresponding authors: E-Mail: 1336504774@qq.com (L.Xu); hope1126@ hotmail.com (Z.Sun) Qi-Yan Li and Yan Wang contributed equally to this work. 


\section{Materials and Methods}

\subsection{Material}

The whole plants of $C$. japonicus were collected in October 2016, from Jilin province of China. This plant material was identified by Prof. Peiming Yang, China State Institute of Pharmaceutical Industry. A voucher specimen (No. 20161012) was deposited in Shanghai University of Medicine \& Health Sciences Central Laboratory. ${ }^{1} \mathrm{H}(600 \mathrm{MHz})$ and ${ }^{13} \mathrm{C}(150 \mathrm{MHz}) \mathrm{NMR}$ spectra were determined using a Bruker Ascend ${ }^{\mathrm{TM}} 600$ spectrometer. HRESIMS data were performed using an Agilent Technologies 6230 Accurate Mass Q-ToF UHPLC/MS spectrometer. Silica gel (200-300 mesh) for column chromatography and GF254 for TLC were purchased from Qingdao Haiyang Chemical Co. Ltd. (Qingdao, China). Optical rotations were measured using a Rudolph Research Autopol I automatic polarimeter. UV and electronic circular dichroism (ECD) spectra were recorded on a JASCO High Performance J-1500 CD spectrometer.

\subsection{Extraction and Isolation}

The whole plants of $C$. japonicus $(5.0 \mathrm{~kg})$ were dried, powdered, and subsequently extracted three times with $80 \% \mathrm{EtOH}$ under continuous reflux. The filtrate was concentrated to obtain a crude extract, which was dissolved in water and then extracted with EtOAc and $n-\mathrm{BuOH}$. The EtOAc fraction (112.5 g) was subjected to silica gel column chromatography (CC) and eluted with a gradient of increasing acetone $(0-100 \%)$ in petroleum to afford six fractions (Fr.1-Fr.6). Fraction Fr. 2 (10.5 g) was subjected to CC over RP18 gel and eluted with $\mathrm{MeOH}-\mathrm{H}_{2} \mathrm{O}$ (35:65-100:0) to give four sub-fractions (Fr.2-1-Fr.2-4). Fr.2-2 was initially eluted with $\mathrm{MeCN}-\mathrm{H}_{2} \mathrm{O}$ (50:50) on an RP C8 column and further purified by semipreparative HPLC with $\mathrm{MeOH}-\mathrm{H}_{2} \mathrm{O}$ (40:60) elution to afford compound 1 (2.0 mg). Fr. $4(8.0 \mathrm{~g})$ was subjected to $\mathrm{CC}$ over RP C18 and eluted with $\mathrm{MeOH}-\mathrm{H}_{2} \mathrm{O}$ in a stepped gradient (30:70-100:0) to afford five sub-fractions (Fr.4-1-Fr.4-5). Fr. 4-3 was separated by semipreparative HPLC eluted with $\mathrm{MeOH}-\mathrm{H}_{2} \mathrm{O}(55: 45)$ to afford compounds 2 (4.0 mg) and $\mathbf{3}(5.0 \mathrm{mg})$.

\subsection{Spectroscopic Data}

Compound 1: White amorphous powder. $[\alpha]_{\mathrm{D}}^{22.5}-70.0(c 0.3, \mathrm{MeOH}) ; \mathrm{UV}(\mathrm{MeOH}) . \lambda_{\max }(\log \varepsilon): 200$ (4.18), 290 (3.40); $\mathrm{ECD}(\mathrm{MeOH}): 200(\Delta \varepsilon+2.53), 215(\Delta \varepsilon-4.08) \mathrm{nm}$; IR, $v_{\max } 3450,2361,1643,671$ $\mathrm{cm}^{-1} ;{ }^{1} \mathrm{H}\left(600 \mathrm{MHz}, \mathrm{CDCl}_{3}\right)$ and ${ }^{13} \mathrm{C}\left(150 \mathrm{MHz}, \mathrm{CDCl}_{3}\right)$ NMR data: Table 1; HRESIMS $\mathrm{m} / z$ 527.2048 $[\mathrm{M}+\mathrm{Na}]^{+}$(calcd for $\left.\mathrm{C}_{30} \mathrm{H}_{32} \mathrm{O}_{7} \mathrm{Na} 527.2156\right), 522.2485\left[\mathrm{M}+\mathrm{NH}_{4}\right]^{+}$(calcd for $\mathrm{C}_{30} \mathrm{H}_{32} \mathrm{O}_{7} \mathrm{NH}_{4}$ 522.2486).

Compound 2: Yellow oil. $[\alpha]_{\mathrm{D}}^{22.5}-25.6(c 0.3, \mathrm{MeOH}) ; \lambda_{\max }(\log \varepsilon)$ : 200 (4.08), 232 (3.53); IR, $v_{\max }$ $3741,2985,2361,1652,1563,1464,1183 \mathrm{~cm}^{-1} ;{ }^{1} \mathrm{H}\left(600 \mathrm{MHz}, \mathrm{CDCl}_{3}\right)$ and ${ }^{13} \mathrm{C}\left(150 \mathrm{MHz}, \mathrm{CDCl}_{3}\right)$ NMR data: Table 2; HRESIMS $m / z 355.1875[\mathrm{M}+\mathrm{Na}]^{+}$(calcd for $\mathrm{C}_{20} \mathrm{H}_{28} \mathrm{O}_{4} \mathrm{Na} 355.1880$ ), 333.3063 $[\mathrm{M}+\mathrm{H}]^{+}$(calcd for $\mathrm{C}_{20} \mathrm{H}_{29} \mathrm{O}_{4} 333.2060$ ).

Compound 3: Yellow oil. $[\alpha]_{\mathrm{D}}^{22.5}-21.7(c 0.3, \mathrm{MeOH}) ; \lambda_{\max }(\log \varepsilon): 200$ (4.15), $232(3.46) ; \mathrm{IR}, v_{\max }$ $3744,2987,2362,1739,1542,1276,685 \mathrm{~cm}^{-1} ;{ }^{1} \mathrm{H}\left(600 \mathrm{MHz}, \mathrm{CDCl}_{3}\right)$ and ${ }^{13} \mathrm{C}\left(150 \mathrm{MHz}, \mathrm{CDCl}_{3}\right)$ NMR data: Table 2; HRESIMS $m / z$ 397.1979 [M + Na $]^{+}$(calcd for $\mathrm{C}_{22} \mathrm{H}_{30} \mathrm{O}_{5} \mathrm{Na}$ 397.1985), 375.2158 $[\mathrm{M}+\mathrm{H}]^{+}$(calcd for $\mathrm{C}_{22} \mathrm{H}_{31} \mathrm{O}_{5} 375.2166$ ).

\subsection{ECD Calculation Method}

Monte Carlo conformational study was carried out by means of the Spartan's 10 software using Merck Molecular Force Field (MMFF). The conformers with Boltzmann-population of over 1\% were chosen for ECD calculations, and then the conformers were initially optimized at B3LYP/6-31+g (d, p) level in methanol using the CPCM polarizable conductor calculation model. The theoretical calculations of ECD were conducted in methanol using time-dependent density functional theory (TD- 
DFT) at the B3LYP/6-31+g (d, p) level for all conformers of the compounds. Rotatory strengths for a total of 30 excited states were calculated. ECD spectra were generated using the program SpecDis 1.6 (University of Würzburg, Würzburg, Germany) and GraphPad Prism 5 (University of California San Diego, USA) from dipole-length rotational strengths by applying Gau6-1-Rian band shapes with sigma $=0.3 \mathrm{eV}$.

\subsection{Inhibitory Effect Against LPS-induced Tumor Necrosis Factor (TNF)- $\alpha$ in RAW264.7 Macrophages}

Briefly, the RAW264.7 cell line was cultured in RPMI medium supplemented with $0.1 \%$ sodium bicarbonate and $2 \mathrm{mM}$ glutamine, penicillin $\mathrm{G}(100 \mathrm{units} / \mathrm{mL})$, streptomycin $(100 \mu \mathrm{g} / \mathrm{mL})$ and $10 \%$ fetal calf serum. The cells were harvested with trypsin-EDTA and diluted to a suspension in a fresh medium. The cells were seeded in the 96-well plates containing $1.0 \times 10^{5}$ cells/well and allowed to adhere for $1 \mathrm{~h}$ at $37^{\circ} \mathrm{C}$ under a humidified atmosphere containing $5 \% \mathrm{CO}_{2}$. Then, the medium was replaced with a fresh medium containing $100 \mu \mathrm{g} / \mathrm{mL}$ of LPS together with the compounds at various concentrations and then incubated for $48 \mathrm{~h}$. The supernatant was transferred into the 96-well ELISA plates and then TNF- $\alpha$ concentrations were determined using commercial ELISA kits. The test compounds were dissolved in DMSO, and the solution was added to RPMI.

\section{Results and Discussion}

\subsection{Structure Elucidation}

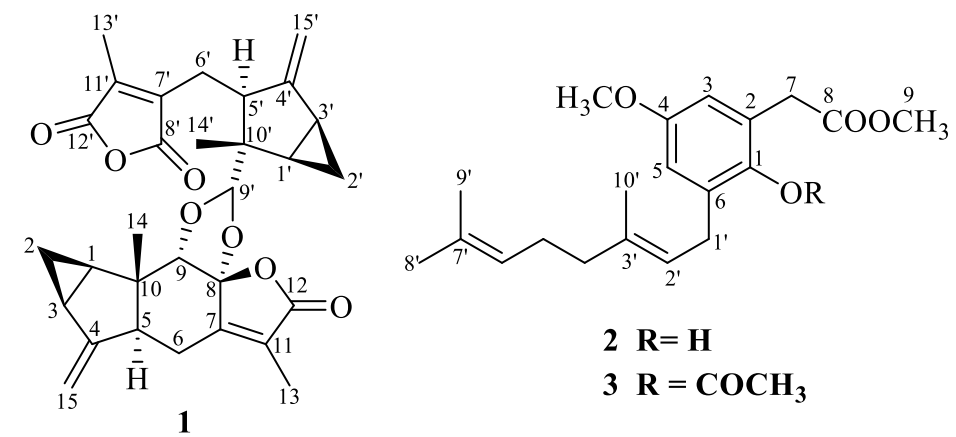

Figure 1. Chemical structures of compounds 1-3

Table 1. ${ }^{1} \mathrm{H}(600 \mathrm{MHz})$ and ${ }^{13} \mathrm{C}(150 \mathrm{MHz}) \mathrm{NMR}$ data for compound $\mathbf{1}$ in $\mathrm{CDCl}_{3}$

\begin{tabular}{cclccl}
\hline Pos. & $\boldsymbol{\delta}_{\mathbf{C}}$ & \multicolumn{1}{c}{$\boldsymbol{\delta}_{\mathbf{H}}(\mathbf{m u l t}, \boldsymbol{J} \mathbf{~ i n ~ H z})$} & Pos. & \multicolumn{1}{c}{$\boldsymbol{\delta}_{\mathbf{C}}$} & \multicolumn{1}{c}{$\boldsymbol{\delta}_{\mathbf{H}}(\mathbf{m u l t}, \boldsymbol{J}$ in Hz) } \\
\hline 1 & 23.5 & $1.84(\mathrm{~m})$ & $1^{\prime}$ & 28.2 & $1.85(\mathrm{~m})$ \\
2 & 15.7 & $0.85(\mathrm{~m}), 0.67(\mathrm{~m})$ & $2^{\prime}$ & 11.2 & $0.81(\mathrm{~m}), 0.70(\mathrm{~m})$ \\
3 & 23.7 & $2.00(\mathrm{~m})$ & $3^{\prime}$ & 25.0 & $1.89(\mathrm{~m})$ \\
4 & 151.8 & & $4^{\prime}$ & 153.5 & \\
5 & 50.4 & $3.42(\mathrm{~m})$ & $5^{\prime}$ & 44.4 & $2.75(\mathrm{dd}, 12.0,5.5)$ \\
6 & 22.3 & $2.46(\mathrm{~m})$ & $6^{\prime}$ & 28.1 & $2.52(\mathrm{ddd}, 13.2,5.5,1.0)$ \\
& & $2.21(\mathrm{~d}, 13.5)$ & & & $2.25(\mathrm{~d}, 12.0)$ \\
7 & 154.6 & & $7^{\prime}$ & 143.6 & \\
8 & 109.7 & & $8^{\prime}$ & 165.8 & \\
10 & 85.4 & $4.26(\mathrm{~s})$ & $9^{\prime}$ & 109.4 & $5.08(\mathrm{~s})$ \\
11 & 42.8 & & $10^{\prime}$ & 48.1 & \\
12 & 127.6 & & $11^{\prime}$ & 142.0 & \\
13 & 171.4 & & $12^{\prime}$ & 166.2 & \\
14 & 8.8 & $1.84(\mathrm{~d}, 1.3)$ & $13^{\prime}$ & 10.3 & $2.01(\mathrm{~s})$ \\
15 & 17.3 & $0.47(\mathrm{~s})$ & $14^{\prime}$ & 15.5 & $1.22(\mathrm{~s})$ \\
\hline & 106.5 & $5.02(\mathrm{brs}), 4.71(\mathrm{brs})$ & $15^{\prime}$ & 107.6 & $4.89(\mathrm{brs}), 4.33(\mathrm{brs})$ \\
\hline
\end{tabular}


Chlojapolactone B (1) was isolated as a white amorphous powder. The molecular formula of $\mathrm{C}_{30} \mathrm{H}_{32} \mathrm{O}_{7}$ was established by HR-ESIMS data and ${ }^{13} \mathrm{C}$ NMR data (Table 1). HRESIMS data displayed a quasi-molecular ion peak at $\mathrm{m} / z 522.2485\left[\mathrm{M}+\mathrm{NH}_{4}\right]^{+}$(calcd for 522.2486), the molecular formula contained 15 degrees of unsaturation. The IR spectrum exhibited characteristic absorption bands of carbonyl $\left(1643 \mathrm{~cm}^{-1}\right)$ groups. In accordance with the molecular formula, 30 carbon resonances consisting of three carbonyls, four double bonds (two tetrasubstituted and two exocyclic), four methylenes, eight methines (two oxygenated), three quaternary carbons (one oxygenated), and four methyls were resolved in the ${ }^{13} \mathrm{C}$ NMR and categorized by DEPT experiments. The ${ }^{1} \mathrm{H}$ NMR spectroscopic data (Table 1) showed two pairs of terminal double bonds $\left(\delta_{\mathrm{H}} 5.02,4.71,4.89,4.33\right)$, four methyl groups $\left(\delta_{\mathrm{H}} 1.84,0.47,2.01,1.22\right)$, two oxygenated methines $\left(\delta_{\mathrm{H}} 5.08\right.$ and 4.26$)$, and four highly upfield-shifted protons $\left(\delta_{\mathrm{H}} 0.85,0.67,0.81,0.70\right)$. The ${ }^{1} \mathrm{H}-{ }^{1} \mathrm{H}$ COSY spectrum showed two sets of proton spin systems in a 1,2-distributed cyclopropane ring $\left(\delta_{\mathrm{H}} 0.67,0.85,1.84\right.$, and $2.00 ; \delta_{\mathrm{H}} 0.70$, $0.81,1.85$, and 1.89). The above data revealed that compound 1 should be a lindenane sesquiterpenoid dimer $[10,19]$. Detailed 2D NMR analysis afforded the basic structure of the two units (unit A and B) as depicted in Figure 2. Unit B was characterized as the typical lindenane-type sesquiterpenoid, chloranthalactone E, by comparing with their NMR data [20]. This was further confirmed by ${ }^{1} \mathrm{H}-{ }^{1} \mathrm{H}$ COSY and HMBC correlations. In unit A, two structural fragments, including cyclopropane ring $(\mathrm{C}$ $1^{\prime}-\mathrm{C}-2^{\prime}-\mathrm{C}-3^{\prime}$ ) and a C-5'-C-6'system were established by the ${ }^{1} \mathrm{H}-{ }^{1} \mathrm{H}$ COSY correlations of $\mathrm{H}-1^{\prime} / \mathrm{H}-$ $2^{\prime} / \mathrm{H}-3^{\prime}$ and $\mathrm{H}-5^{\prime} / \mathrm{H}-6^{\prime}$. The HMBC correlations of $\mathrm{H}_{3}-14^{\prime}$ to $\mathrm{C}-1^{\prime}, \mathrm{C}-5^{\prime}, \mathrm{C}-9^{\prime}$ and $\mathrm{C}-10^{\prime}$ allowed to establish the connection of $\mathrm{C}-1^{\prime}, \mathrm{C}-5^{\prime}, \mathrm{C}-9^{\prime}$ and $\mathrm{C}-14^{\prime}$ to the quaternary carbon $\mathrm{C}-10^{\prime}$. The linkage of C-6'-C-7'-C-8' was revealed by the HMBC correlations of $\mathrm{H}-6^{\prime} / \mathrm{C}-7^{\prime}$ to $\mathrm{C}-8^{\prime}$, while the HMBC correlations from $\mathrm{H}_{3}-13^{\prime}$ to $\mathrm{C}-7^{\prime}, \mathrm{C}-11^{\prime}$, and $\mathrm{C}-12^{\prime}$, as well as from $\mathrm{H}-6^{\prime}$ to $\mathrm{C}-7^{\prime}$ and $\mathrm{C}-11^{\prime}$ suggested the $\mathrm{C}-7^{\prime}-\mathrm{C}-11^{\prime}-\mathrm{C}-12^{\prime}$ linkage pattern. The upfield-shifted carbonyls at $\mathrm{C}-8^{\prime}$ and $\mathrm{C}-12^{\prime}$ required an oxygen bridge between $\mathrm{C}-8^{\prime}$ and $\mathrm{C}-12^{\prime}$, which eventually formed a 3-methyl-2,5-furandione moiety in unit $\mathrm{A}$. As the above-mentioned structural elucidation already accounted for 14 out of the 15 degrees of unsaturation, the remaining one thus required the presence of an additional ring to link units $\mathrm{A}$ and B. In the HMBC spectrum, obvious correlations from $\mathrm{H}_{-} 9^{\prime}$ to the ketal carbon at C-8 and C-9, as well as the correlations of $\mathrm{H}-9 / \mathrm{C}-9^{\prime}$ suggested the presence of two oxygen bridges between C-9' and C-8, C-9' and C-9, respectively. Based on the acetal nature of C-9' and downfield chemical shift of C-8, two oxygen bridges are required to form a 1,3-dioxine ring. Thus, the planar structure of $\mathbf{1}$ was elucidated as depicted, with a 1,3-dioxolane ring linking two lindenane sesquiterpenoid units.

The relative configuration of $\mathbf{1}$ was established by NOESY experiment and by comparing the NMR data with those known lindenane monomers. In unit $\mathrm{B}$, the correlations of $\mathrm{H}-2 \beta / \mathrm{H}_{3}-14$, and $\mathrm{H}_{3}-$ $14 / \mathrm{H}-6 \beta$ indicated that these protons were cofacial and arbitrarily assigned as $\beta$-orientation, while $\mathrm{H}$ $2 \alpha, \mathrm{H}-1, \mathrm{H}-3$, and $\mathrm{H}-5$ were as $\alpha$-oriented by the NOESY correlations of $\mathrm{H}-2 \alpha / \mathrm{H}-1, \mathrm{H}-3$ and the large coupling constants between $\mathrm{H}-5$ and $\mathrm{H}-6 \beta\left(J=13.0 \mathrm{~Hz}\right.$ ) (Figure 2). The $\mathrm{H}_{3}-14$ methyl signal at $\delta_{\mathrm{H}} 0.47$ supported syn-relationship of the C-14 methyl group and 8-oxygen atom, suggesting C-8-O-C-12 in $\beta$-orientation [21, 22]. Meanwhile, the 1D NMR data of the chiral centers in unit $\mathrm{B}$ were consistent with those reported in its analogues $[10,23]$. As for unit A, the NOESY correlations of $\mathrm{H}_{3}-14^{\prime} / \mathrm{H}-2^{\prime} \beta$ indicated that these protons were cofacial and arbitrarily assigned as $\beta$-oriented. In consequence, the NOESY correlations of $\mathrm{H}-5^{\prime} / \mathrm{H}-3^{\prime}$ and $\mathrm{H}-5^{\prime} / \mathrm{H}-1^{\prime}$ revealed that these protons were $\alpha$-oriented. In addition, the NOESY correlations of $\mathrm{H}-9 / \mathrm{H}-9^{\prime}$ indicated that these protons were co-facial on the 1,3dioxolane ring. Above mentioned NOESY correlations confirmed the relative configuration of $\mathbf{1}$ was similar with that of chlojapolactone A [10]. The absolute configuration of compound $\mathbf{1}$ was determined by comparison the experimental and the computational ECD spectra. As shown in Figure 3 , the ECD spectrum of 1 showed a negative Cotton effect at $215 \mathrm{~nm}\left(\pi \rightarrow \pi^{*}\right.$ transition $)$ due to the transition interaction between the $\alpha, \beta$-unsaturated ketone and furan dione chromophores. The calculated ECD curve of enantiomer configuration of $\left(1 R, 3 S, 5 S, 8 S, 9 S, 10 S, 1^{\prime} R, 3^{\prime} S, 5^{\prime} S, 9^{\prime} R, 10^{\prime} S\right)-1$ matched well with the experimental one, assigning unambiguously the absolute configuration of compound 1 as $1 R, 3 S, 5 S, 8 S, 9 S, 10 S, 1^{\prime} R, 3^{\prime} S, 5^{\prime} S, 9^{\prime} R, 10^{\prime} S$. In addition, from the prospective of biosynthesis pathway, compound $\mathbf{1}$ could be considered as a precursor of chlojapplactone A. Therefore, this assignment was consistent with the biogenetic origin of lindenane-type sesquiterpenoids from the genus Chloranthus. Thus, compound $\mathbf{1}$ was assigned as depicted. 


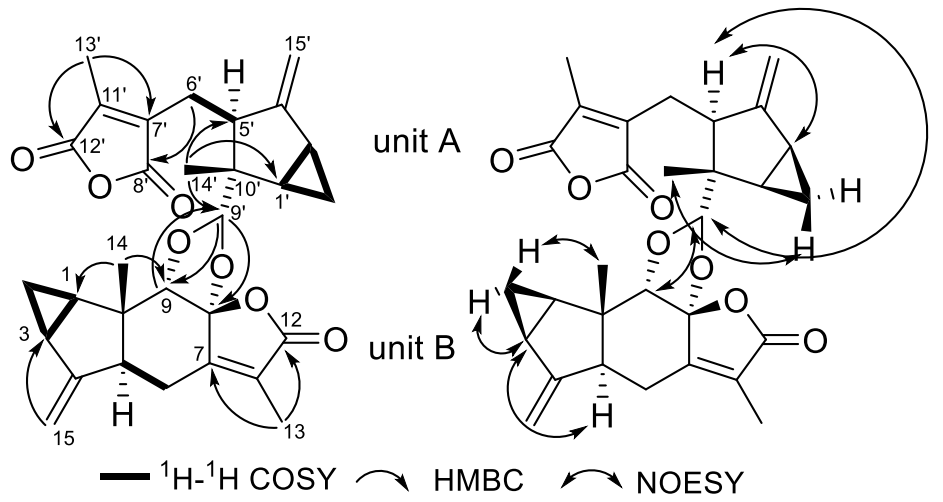

Figure 2. The key ${ }^{1} \mathrm{H}-{ }^{1} \mathrm{H}$ COSY, HMBC and NOESY correlations of compound 1

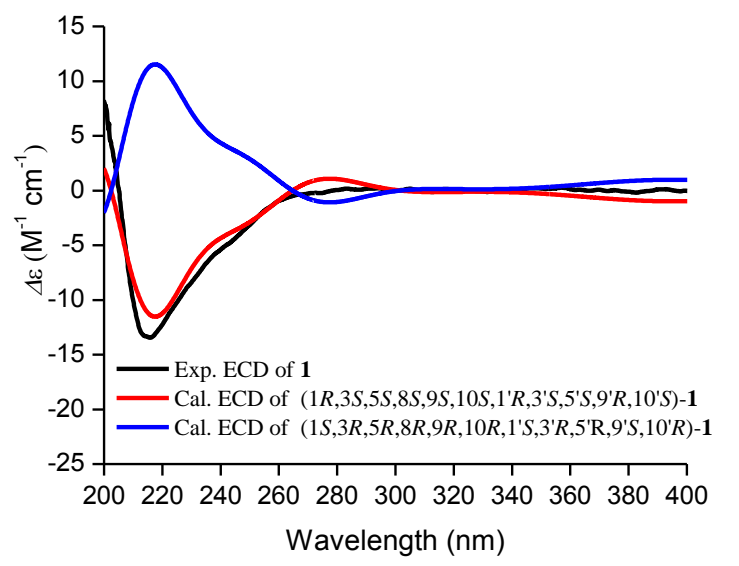

Figure 3. Calculated and experimental ECD spectra of 1

Compound 2 was assigned to a molecular formula of $\mathrm{C}_{20} \mathrm{H}_{28} \mathrm{O}_{4}$ by HRESIMS ion at $\mathrm{m} / \mathrm{z}$ $333.2063[\mathrm{M}+\mathrm{H}]^{+}$(calcd for 333.2060). A strong absorption at $1652 \mathrm{~cm}^{-1}$ in the IR spectrum suggested the presence of a carbonyl group. The ${ }^{1} \mathrm{H}$ and ${ }^{13} \mathrm{C}$ NMR spectral data of 2 were similar to those of denudaquinol [24], the major difference being the presence of a methoxy group. The key HMBC correlations of $-\mathrm{OCH}_{3} / \mathrm{C}-4$ suggested that the methoxy group was located at $\mathrm{C}-4$. Therefore, the structure of $\mathbf{2}$ was characterized to be 4-methoxyl-denudaquinol. Compound $\mathbf{3}$ was isolated as yellow colored oil. A protonated molecular ion at $\mathrm{m} / z 375.2158\left([\mathrm{M}+\mathrm{H}]^{+}\right.$, calcd for 375.2166) indicated a molecular formula of $\mathrm{C}_{22} \mathrm{H}_{30} \mathrm{O}_{5}$. The ${ }^{1} \mathrm{H}$ and ${ }^{13} \mathrm{C}$ NMR spectral data of $\mathbf{3}$ was comparable to that of 2 . The main difference was the presence of an acetyl group. The $\mathrm{HMBC}$ correlations of $-\mathrm{CH}_{3}\left(\delta_{\mathrm{H}} 2.29\right)$ to the carbonyl carbon $\left(\delta_{\mathrm{c}}\right.$ 169.5) and $\mathrm{C}-1$ indicated that the acetoxy group was located at the $\mathrm{C}-1$ position. The structure of $\mathbf{3}$ was established as 1-acetyl-4-methoxyl-denudaquinol. Because methanol and ethanol were used in the extraction and isolation process, compounds $\mathbf{2}$ and $\mathbf{3}$ might be artificial products.

Chlojapolactone B (1) was evaluated for its inhibitory effect against LPS induced TNF- $\alpha$ production in RAW264.7 macrophages. Compound 1 exhibited moderate inhibition against TNF- $\alpha$ with an IC $_{50}$ value of $76.16 \mu \mathrm{M}$, which was comparable to the positive control triptolide $\left(\mathrm{IC}_{50}=11.50 \mu \mathrm{M}\right)$. 
Table 2. ${ }^{1} \mathrm{H}(600 \mathrm{MHz})$ and ${ }^{13} \mathrm{C}(150 \mathrm{MHz})$ NMR data for compounds 2 and $\mathbf{3}$ in $\mathrm{CDCl}_{3}$

\begin{tabular}{cccll}
\hline \multirow{2}{*}{ Pos. } & \multicolumn{1}{c}{$\mathbf{2}$} & \multicolumn{1}{c}{$\mathbf{3} \mathbf{c}$} & \multicolumn{1}{c}{$\boldsymbol{\delta}_{\mathbf{H}}(\mathbf{m u l t}, \boldsymbol{J}$ in Hz) } \\
\cline { 2 - 5 } & $\boldsymbol{\delta} \mathbf{C}$ & \multicolumn{1}{c}{$\boldsymbol{\delta}_{\mathbf{H}}(\mathbf{m u l t}, \boldsymbol{J}$ in Hz) } & 141.3 & \\
2 & 147.2 & & 127.7 & \\
3 & 121.7 & & 113.8 & $6.69(\mathrm{~d}, 3.0)$ \\
4 & 113.7 & $6.54(\mathrm{~d}, 3.0)$ & 157.4 & \\
5 & 153.4 & & 114.7 & $6.70(\mathrm{~d}, 3.0)$ \\
6 & 115.0 & $6.65(\mathrm{~d}, 3.0)$ & 135.4 & \\
7 & 130.5 & & 37.0 & $3.68(\mathrm{~s})$ \\
8 & 37.6 & $3.64(\mathrm{~s})$ & 171.3 & \\
9 & 174.0 & & 52.3 & $3.68(\mathrm{~s})$ \\
$1^{\prime}$ & 52.7 & $3.73(\mathrm{~s})$ & 28.9 & $3.36(\mathrm{~d}, 7.2)$ \\
$2^{\prime}$ & 29.6 & $3.36(\mathrm{~d}, 7.2)$ & 121.2 & $5.23(\mathrm{brt}, 7.2)$ \\
$3^{\prime}$ & 121.9 & $5.31(\mathrm{brt}, 7.2)$ & 137.6 & \\
$4^{\prime}$ & 138.0 & & 39.8 & $2.04(\mathrm{~m})$ \\
$5^{\prime}$ & 39.9 & $2.07(\mathrm{~m})$ & 26.8 & $2.09(\mathrm{~m})$ \\
$6^{\prime}$ & 26.7 & $2.11(\mathrm{~m})$ & 124.2 & $5.10(\mathrm{brt}, 7.0)$ \\
$7^{\prime}$ & 124.2 & $5.09(\mathrm{brt}, 6.7)$ & 131.8 & \\
$8^{\prime}$ & 131.9 & & 17.9 & $1.60(\mathrm{~s})$ \\
$9^{\prime}$ & 17.8 & $1.60(\mathrm{~s})$ & 25.8 & $1.68(\mathrm{~s})$ \\
$1^{\prime}$ & 25.8 & $1.68(\mathrm{~s})$ & 16.3 & $1.67(\mathrm{~s})$ \\
$\mathrm{OCH}_{3}$ & 16.3 & $1.74(\mathrm{~s})$ & 55.6 & $3.77(\mathrm{~s})$ \\
$-\mathrm{COCH}_{3}$ & 55.8 & $3.74(\mathrm{~s})$ & 169.5 & \\
& & & 20.6 & $2.29(\mathrm{~s})$ \\
\hline
\end{tabular}

\section{Conclusion}

As part of our ongoing study on the traditional herbal medicines in China. We have investigated the chemical constituents of $C$. japonicus to isolate one new dimeric lindenane sesquiterpenoid and two new phenolic derivatives. Chlojapolactone B (1), a novel lindenane sesquiterpenoid dimer featuring a rare 1,3-dioxolane linkage between an 8,9-seco lindenane and a lindenane sesquiterpenoid. The planar structures of these compounds were determined by 1D and 2D NMR as well as by HRESIMS spectral analysis. The absolute configuration of $\mathbf{1}$ was elucidated by ECD spectroscopic analyses. These compounds might contribute the chemical diversity of $C$. japonicus.

\section{Acknowledgments}

This work was funded by National Natural Science Fund (No. 81872418); Shanghai Natural Science Foundation (18ZR1431700); Shanghai Municipal Health and Family Planning Commission Project (201540027, 20174Y0232, 20174Y0236, and 20184Y0104), The seed fund program of Shanghai university of medicine \& health Sciences (HSMF-17-22-031, SFP-18-21-15-003, and SPF18-20-15-001)

The Municipal Human Resources Development Program for Outstanding Young Talents in Medical and Health Sciences in Shanghai (2017YQ048); Shanghai Putuo district municipal commission of health research fund (KW-2017-04); Shanghai Fengxian District Science and Technology Project (20181601). 


\section{Supporting Information}

Supporting information accompanies this paper on http://www.acgpubs.org/journal/records-of$\underline{\text { natural-products }}$

\section{ORCID}

Qiyan Li: 0000-0002-0222-8610

Yan Wang: 0000-0002-0379-9386

Songsong Wen: 0000-0003-4972-5910

Ying Wu: $\underline{0000-0002-2051-4725}$

Lihua Xu: 0000-0002-2272-2931

Zhenliang Sun: $\underline{0000-0002-7651-0600}$

\section{References}

[1] Editor committee, Chinese Herb, Vol.8 Shanghai Science and Technology Publisher, Shanghai, 1999, pp. 449-459.

[2] C. S. Jiang, Y.Q. Guo, S. Yin, H. Zhang and G.H. Tang (2018). A new lindenane-type sesquiterpenoid lactone from Chloranthus japonicas, J. Asian Nat. Prod. Res. 20(1), 1-7.

[3] Z. G. Zhuo, G. Z. Wu, X. Fang, X. H. Tian, H.Y. Dong, X. K. Xu, H. L. Li, Xie N, W. D. Zhang and Y. H. Shen (2017). Chlorajaponols A-F, sesquiterpenoids from Chloranthus japonicus and their in vitro anti-inflammatory and anti-tumor activities, Fitoterapia 119, 90-99.

[4] Z. G. Zhuo, Z. Y. Cheng, J. Ye, H. L. Li, X. K. Xu, N. Xie, W. D. Zhang and Y. H. Shen (2017). Two new sesquiterpenoids and a new lindenane sesquiterpenoid dimer from Chloranthus japonicas, Phytochem. Lett. 20, 133-138.

[5] J. Kawabata, Y. Fukushi, S. Tahara and J. Mizutani (1990). Shizukaol A, a sesquiterpene dimer from Chloranthus japonicas, Phytochemistry 29(7), 2332-2334.

[6] O. E. Kwon, H. S Lee., S. W. Lee, K. Bae, K. Kim, M. Hayashi, M. C. Rho and Y. K. Kim (2006). Dimeric sesquiterpenoids isolated from Chloranthus japonicus inhibited the expression of cell adhesion molecules, J. Ethnopharmacol. 104, 270-277.

[7] Y. Q. Guo, J. J. Zhao, Z. Z. Li, G. H. Tang, Z. M. Zhao and S. Yin (2016). Natural nitric oxide (NO) inhibitors from Chloranthus japonicas, Bioorg. Med. Chem. Lett. 26(13), 3163-3166.

[8] J. J. Zhao, Y. Q. Guo, D. P. Yang, X. Xue, Q. Liu, L. P. Zhu, S. Yin and Z. M. Zhao (2016). Chlojaponilactone B from Chloranthus japonicus: suppression of inflammatory responses via inhibition of the NF-кB signaling pathway, J. Nat. Prod. 79(9), 2257-2263.

[9] H. Yan, M. Y. Ba, X. H. Li, J. M. Guo, X. J. Qin, L. He, Z. Q. Zhang, Y. Guo and H. Y. Liu (2016). Lindenane sesquiterpenoid dimers from Chloranthus japonicus inhibit HIV-1 and HCV replication, Fitoterapia 115, 64-68.

[10] Y. Q. Guo, G. H. Tang, Z. Z. Li, S. L. Lin and S. Yin (2015). Chlojapolactone A, an unprecedented 1, 3dioxolane linked-lindenane sesquiterpenoid dimer from Chloranthus japonicas, RSC Adv. 5 (125), 103047-103051.

[11] M. Uchida, Y. Koike, G. Kusano, Y. Kondo, S. Nozoe, C. Kabuto and T. Takemoto (1980). Studies on the constituents of Chloranthus spp. III. Six sesquiterpenes from Chloranthus japonicas, Chem. Pharm. Bull. 28(1), 92-102.

[12] S. Tahara, Y. Fukushi, J. Kawabata and J. Mizutani (1981). Lindenanolides in the root of Chloranthus japonicus (Chloranthaceae), Agric. Biol. Chem. 45(6), 1511-1512.

[13] J. Kawabata, S. Tahara and J. Mizutani (1981). Isolation and structural elucidation of four sesquiterpenes from Chloranthus japonicus (Chloranthaceae), Agric. Biol. Chem. 45(6), 1447-1453.

[14] J. Kawabata, E. Fukushi and J. Mizutani (1995). Sesquiterpene dimers from Chloranthus japonicas, Phytochemistry 39(1), 121-125.

[15] P. L. Fang, Y. L. Cao, H. Yan, L. L. Pan, S. C. Liu, N. B. Gong, Y. Lü, C. X. Chen, H. M. Zhong, Y. Guo and H. Y. Liu (2011). Lindenane disesquiterpenoids with anti-HIV activity from Chloranthus japonicas, J. Nat. Prod. 74, 1408-1413.

[16] J. Kawabata, E. Fukushi, and J. Mizutani (1998). Sesquiterpene dimer and trimer from Chloranthus japonicas, Phytochemistry 47(2), 231-235. 
[17] R. Hu, H. Yan, X. Hao, H. Liu and J. Wu (2013). Shizukaol D isolated from Chloranthus japonicas inhibits AMPK-dependent lipid content in hepatic cells by inducing mitochondrial dysfunction, PloS One 8(8), e73527.

[18] H. Yan, X. J. Qin, X. H. Li, Q. Yu, W. Ni, L. He and H. Y. Liu (2019). Japonicones A-C: Three lindenane sesquiterpenoid dimers with a 12-membered ring core from Chloranthus japonicas, Tetrahedron Lett. 60(10), 713-717.

[19] A. R. Wang, H. C. Song, H. M. An, Q. Huang, X. Luo and J. Y. Dong (2015). Secondary metabolites of plants from the genus Chloranthus: chemistry and biological activities, Chem. Biodivers. 12(4), 451-473.

[20] Y. Takeda, H. Yamashita, T. Matsumoto and H. Terao (1993). Chloranthalactone F, a sesquiterpenoid from the leaves of Chloranthus glaber, Phytochemistry 33(3), 713-715.

[21] I. Kouno, A. Hirai, A. Fukushige, Z. H. Jiang and T. Tanaka (2001). New eudesmane sesquiterpenes from the root of Lindera strychnifolia, J. Nat. Prod. 64(3), 286-288.

[22] C. F. Zhang, N. Nakamura, S. Tewtrakul, M. Hattori, Q. S. Sun, Z. T. Wang and T. Fujiwara (2002). Sesquiterpenes and alkaloids from Lindera chunii and their inhibitory activities against HIV-1 integrase, Chem. Pharm. Bull. 50(9), 1195-1200.

[23] Y. Y. Fan, Y. L. Sun, B. Zhou, J. X. Zhao, L. Sheng, J. Y. Li and J. M. Yue (2018). Hedyorienoids A and B, two sesquiterpenoid dimers featuring different polycyclic skeletons from Hedyosmum orientale, Org. Lett. 20(17), 5435-5438.

[24] T. Noshita, H. Kiyota,Y. Kidachi, K. Ryoyama, S. Funayama, K. Hanada and T. Murayama (2009). New cytotoxic phenolic derivatives from matured fruits of Magnolia denudate, Biosci. Biotech. Bioch. 73(3), 726-728.

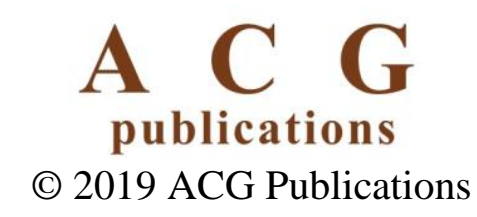

